\title{
Aplicação da Metodologia Ativa de Aprendizagem na disciplina de Fundamentos de Eletrônica do curso de Bacharelado em Ciência da Computação para se Evitar a Evasão
}

\section{Sara Moreira da Silva ${ }^{1}$, Fernando Yoiti Obana ${ }^{2}$, Max Robert Marinho ${ }^{2}$, Edinaldo Serra Cardoso Júnior ${ }^{3}$, Thalita Oliveira Rocha ${ }^{3}$, Lucas Kriesel Sperotto ${ }^{2}$}

${ }^{1}$ Bolsista de Iniciação Cientifica 2019 - UNEMAT - Campus da Universidade do Estado de Mato Grosso em Alto Araguaia - MT - Brasil

${ }^{2}$ Departamento de Computação

Universidade do Estado de Mato Grosso (UNEMAT) - Alto Araguaia, MT - Brasil

${ }^{3}$ Bolsista de Iniciação Cientifica 2019 - Cooperação FAPEMAT/UNEMAT - Campus da Universidade do Estado de Mato Grosso em Alto Araguaia - MT - Brasil

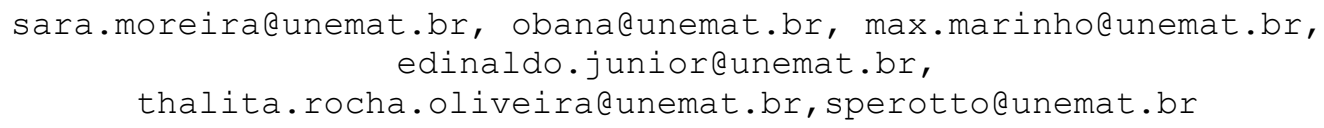

\begin{abstract}
Evasion in exact sciences undergraduate courses is a problem that all higher education institutions are suffering from. This work brings the study and application of Active Learning Methodologies in the Electronics Fundamentals discipline of the Computer Science course at UNEMAT in Alto Araguaia with the objective of reducing dropout and increasing the permanence of students in this discipline, in an attempt to reduce the evasion. Two different active methodologies are used, the problem-based and the project-based, and the results were evaluated during four sequential semesters.
\end{abstract}

Resumo. A evasão em cursos de graduação em ciências exatas é um problema que todas as instituições de ensino superior estão sofrendo. Esse trabalho vem trazer o estudo e a aplicação de Metodologias de Aprendizagem Ativas na disciplina de Fundamentos de Eletrônica do curso de Ciência da Computação da UNEMAT de Alto Araguaia com o objetivo de reduzir a desistência e aumentar a permanência dos alunos nesta disciplina, na tentativa de se reduzir a evasão. São utilizadas duas metodologias ativas diferentes, a baseada em problemas e a baseada em projetos, e os resultados foram avaliados durante quatro semestres sequenciais.

\section{Introdução}

Nos países desenvolvidos existe uma preocupação com o grande número de desistências e a falta de motivação nos cursos de ciências exatas e ciências básicas, que tem como consequência a redução de profissionais nestas área, razão suficiente para preocupar a atual geração (VALLIM et al., 2009). Atrair alunos que iniciem um curso na área de exatas e que permaneça no mesmo até sua conclusão depende muito dos docentes e da própria Instituição de Ensino Superior (IES). Para solucionar este problema algumas das soluções são projetos de pesquisa, de extensão e de ensino são elaborados, dentro das 
universidades, e aulas mais atrativas são construídas pelos docentes, como tentativas de se motivar os alunos para que terminem o curso que iniciaram e sigam carreira em sua área de formação.

Apesar das melhorias, a infraestrutura educacional no Brasil é muito deficitária. Uma pesquisa feita pelo Saeb (Sistema de Avaliação da Educação Básica), divulgada pelo MEC (Ministério da Educação) em 2017 relatava a precariedade da educação básica do Brasil. O diagnóstico mostrava que a cada dez alunos do $3^{\circ}$ ano do ensino médio, sete deles possuem um conhecimento escasso em disciplinas básicas que são o português e a matemática, (VANESSA FAJARDO E FLAVIA FOREQUE, ).

O conhecimento e a aprendizagem da matemática e do português são a base para o futuro de um jovem ou de qualquer pessoa que queira entrar em uma faculdade, desejo de muitas pessoas que sonham em fazer um superior. Para aqueles que desejam seguir uma carreira ou fazer um curso em ciências exatas, mais especificadamente, realizar cursos de engenharias ou cursos tecnológicos, a matemática é muito importante, e o déficit deste conhecimento gera desistências e possivelmente evasão em massa (SILVA, 2018).

Para (CARVALHO; SANTOS; NAKAMURA; OLIVEIRA, 2019) o índice alto de evasão na área da Computação é um grande problema, tanto para o mercado de trabalho quanto para o processo de formação. O âmbito de formação profissional envolve custos financeiros e pessoais, tornando o problema mais complicado de ser resolvido, pois tornase impossível isolar todos os fatores envolvidos, custos esses que vão desde os meios de seleção de candidatos até as metodologias de ensino e aprendizagem e gestão dos cursos.

O mercado de trabalho está em constante desenvolvimento e a era das novas tecnologias está invadindo os campos de empregos e estudos. Nota-se que dispositivos modernos estão substituindo seres humanos em ocupações menos tecnológicas, obtendo melhor desempenho e fornecendo mais facilidade para os usuários. Essa transição do mercado de trabalho nos mostra que o futuro está sendo transformado por novas invenções absorvidas pelas novas tecnologias que são desenvolvidas pelos jovens da atualidade (SILVA, 2018).

Um exemplo é o Google, uma empresa global que simplesmente se apodera desse conhecimento usando novos métodos para obter ganhos. Uma metodologia que é utilizada na empresa Google é chamada de OKR Objectives and Key Results (objetivos e resultados-chave), o OKR determina a maneira como a área e o indivíduo trabalham, além do Google, essa metodologia é utilizadas por diversas startups no Vale do Silício (LABS, ).

Segundo (TEODORO, N. M. 2010) as atividades que os professores desenvolvem junto aos seus alunos tem uma influência crucial na evasão escolar e na frustação do aluno. Em outras palavras, as condutas pedagógicas dos professores, ou seja, o método que estão utilizando no processo de ensino trazem resultados positivos ou negativos no processo de aprendizagem do aluno. A fim de reduzir desistências e evasões e aprimorar o ensino, novas metodologias de ensino estão dominando o mercado de trabalho e as instituições de ensino, criando avanços no processo de ensino-aprendizagem. Um avanço no estudo sobre metodologias de aprendizagem resultou nas Metodologias Ativas de Aprendizagem, que favorecem a aprendizagem dos alunos e despertam a sua curiosidade, como também fornecem autonomia, fazendo com que decisões, sejam tomadas com mais facilidade, na escola e na sociedade. (BORGES; ALENCAR, 2014). 
O Curso de Ciência da Computação da Universidade do estado de Mato Grosso, Campus de Alto Araguaia possui um índice de evasão e desistência alto, não somente por ser um curso de ciências exatas, mas pelas diversas características de seu corpo discente, chegando a $50 \%$ em turmas de semestres mais avançados. Assim, este trabalho propõe um estudo utilizando as Metodologias Ativas, inseridas na disciplina de Fundamentos de Eletrônica, do $3^{\circ}$ Semestre do curso de Ciência da Computação da UNEMAT de Alto Araguaia, por meio de um projeto final da disciplina para a construção de um Circuito Oscilador com Contador de Décadas, no formato do Reator ARC dos filmes do Homem de Ferro. Utilizando-se do sucesso da série de filmes do Homem de Ferro como um dos atrativos para a disciplina o objetivo do estudo é de se avaliar o aumento de interesse dos alunos para com seu curso de graduação, com o intuito de se reduzir a evasão. Este trabalho se divide em 5 capítulos principais onde o capítulo 1 aborda a introdução deste trabalho trazendo os principais pontos a serem estudados e analisados, apresentando o objetivo da proposta; o capítulo 2 traz a conceituação sobre as metodologias de aprendizagem ativas de aprendizagem que surgiram nos últimos anos; o capítulo 3 traz a forma com que as metodologias ativas escolhidas foram utilizadas, e os materiais utilizados para a proposta deste trabalho, bem como a forma de uso dos mesmos; o capítulo 4 apresenta os resultados obtidos no decorrer dos semestre avaliados; e o capítulo 5 traz as conclusões sobre este trabalho, seguido das referências utilizadas.

\section{Metodologias Ativas de Aprendizagem}

Métodos tradicionais de ensino baseados em memorização são cansativos, estressantes e também desmotivadores, e como consequência desses métodos, muitos alunos se desinteressam pelo conteúdo exposto e desviam sua atenção para outros assuntos mais atrativos, que geralmente não é o conteúdo da aula (ALBRECHT; KRÜGER, 2013). As novas metodologias de ensino/aprendizagem não vieram para que as antigas práticas de ensino sejam abruptamente esquecidas ou inutilizadas. É necessário que estas novas metodologias de ensino/aprendizagem se mostrem eficientes e apresentem resultados positivos, para que possam ser amplamente utilizadas no meio de ensino.

Podendo ser definida como estratégias de ensino com enfoque na aprendizagem ativa dos alunos, as metodologias ativas podem ser classificadas em: aprendizagem por pares, aprendizagem baseada em problemas, aprendizagem baseada em projetos, sala de aula invertida, ensino hibrido, dentre outras metodologias que são tão eficazes quanto estas (LÁZARO; SATO; TEZANI, 2018).

De acordo com (MORAN, 2017), metodologias são influentes diretivas que conduzem estratégias de processos do ensino/aprendizagem com suas técnicas e abordagens diferenciadas e especificadamente concretas, complementando assim que as metodologias ativas são orientações estratégicas centralizadas efetivamente na construção do processo de ensino/aprendizagem dos estudantes de uma forma sistemática e flexível.

São diversas as maneiras com a qual aprendemos, porém se obtém técnicas e procedimentos diferentes para conseguir alcançar os resultados desejados. Segundo o psiquiatra americano William Glasser juntamente com Freire (1987), Rosso e Taglieber (1992), destacam que a aprendizagem somente será significativa quando a prática pedagógica que foi implantada a tempos, deixar de ser um processo passivo onde o 
docente é o protagonista com suas didáticas de memorização e aplicação de avaliações, sendo que o aluno é quem deveria ser o principal agente do processo de ensino/aprendizagem. Em sua pesquisa, William Glasser reforça ainda com mais ênfase a ideia do uso da diversificação metodológica do processo ensino/aprendizagem sendo esses métodos mais efetivos. (SILVA, 2019).

Na Figura 1 é possível observar que William Glasser desbravou os métodos de aprendizagem mais eficazes e consequentemente os menos eficazes, gerando um esquema que avalia a veracidade dos métodos de ensino/aprendizagem.

\section{A PIRÂMIDE DE APRENDIZAGEM DE WILLIAM GLASSER}

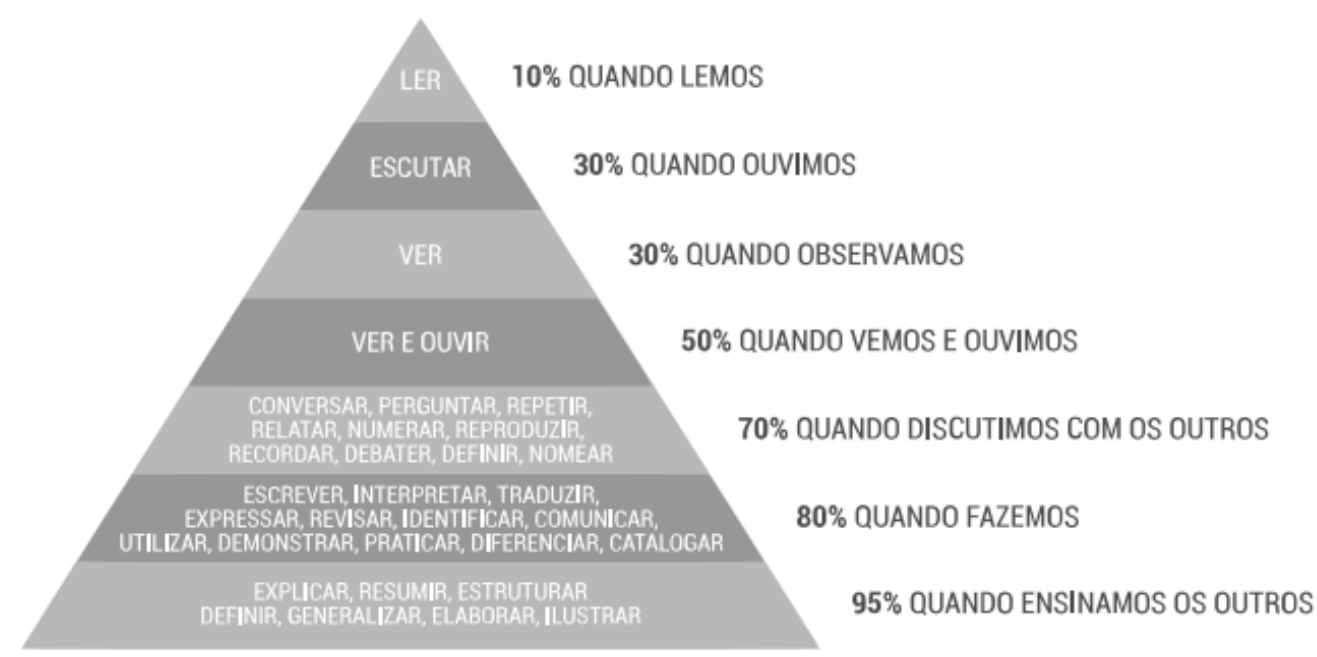

Figura 1. Pirâmide da aprendizagem.

Fonte: https://recto.com.br/download/recto-descomplicando-a-aprendizagem.pdf (Acessado em 25 de agosto de 2020).

Dentre as metodologias ativas existentes, foram utilizadas para este trabalho a metodologia de Aprendizagem Baseada em Projetos (Project-Based Learning) e Aprendizagem Baseada em Problemas (Problem-Based Learning - PBL), que são uma classificação de aprendizagem colaborativa, tendo em vista que o ensino superior, mesmo presencial, possui ricas ações significativas para a aprendizagem com as metodologias ativas e colaborativas. (OLIVEIRA et al., 2015)

A aprendizagem baseada em projetos desenvolvida por John Dewey (1859-1952), defende a capacidade de pensar "mediante o aprender a fazer" e diferente da forma tradicional, essa metodologia promove um vínculo entre o aluno e a aprendizagem. Essas atividades são elaboradas em torno de um problema relevante cujo principal objetivo é obter um produto final, por meio de decisões, pesquisa, pensamento crítico criativo e habilidades, com a finalidade de construir algo novo e criativo no processo ou no resultado (LÁZARO; SATO; TEZANI, 2018).

A aprendizagem baseada em problemas surgiu na década de 1960 no Canadá na universidade McMaster, e também na universidade Maastricht situada na Holanda, inicialmente em escolas de medicina, apesar de ser usada também em outras áreas de conhecimento como Computação, Engenharias, dentre outras (MORAN, 2017). 
Caracterizada como uma metodologia estratégica, dá ao aluno a possibilidade de trabalhar em prol da resolução de um determinado problema, de maneira que o agente principal e total responsável por seu aprendizado passa ser o aluno. Diante disso o professor tornase responsável por elaborar a tarefa e propor problemas, dos quais os alunos ficam responsáveis pela busca de novas soluções e do conhecimento para resolve-los. Portanto essa proposta caminha em direção a formação de um discente autônomo, capaz de trabalhar individualmente e em grupo, buscando soluções adequadas para o problema e desenvolvendo novas habilidades (LÁZARO; SATO; TEZANI, 2018).

De acordo com (GEWEHR et al., 2016), essas metodologias permitem a inserção de novos elementos nas aulas, mostrando um grande potencial na indagação e despertando a curiosidade dos alunos, além de trazer novas perspectivas de ensino ao professor. Como prerrogativa dos métodos ativos, os alunos acabam desenvolvendo maior confiança na tomada de decisões, maior engajamento e persistência de presença nas aulas, além de uma melhora expressiva na comunicação oral e na escrita.

\section{Métodos e Materiais Utilizados}

Nesta seção será abordado a forma com as metodologias de aprendizagem de aprendizagem foram utilizadas e aplicadas na disciplina de Fundamentos de Eletrônica e os materiais necessários para a construção do Reator ARC.

\subsection{Aplicação das Metodologias Ativas}

A metodologia ativa de aprender baseando-se em projetos propõe que os alunos analisem um problema e tentem resolvê-lo, chegando assim a uma solução, individual ou em grupo, dando independência ao aluno à finalização de um projeto proposto. Para alcançar a conclusão do projeto é utilizada outra metodologia ativa de aprendizagem, a metodologia ativa baseada em problemas, que faz com que o aluno produza seu próprio conhecimento conceitual e procedimental por meio de pequenos problemas propostos, expondo o aluno a situações mais motivadoras. Esta metodologia, diferentemente da metodologia ativa baseada em problema, tem seu foco na parte teórica na resolução de casos.

Os conteúdos utilizados para a disciplina de Fundamento de Eletrônica, que são referência para o entendimento do principais conceitos para o desenvolvimento deste trabalho, estão disponibilizadas no site https://sites.google.com/site/fyobana/material/fe. Os conteúdos abordados encontram-se de acordo com o currículo de referência da SBC para um curso de Ciência da Computação para uma disciplina que aborda temas relacionados a sistemas e circuitos digitais. A proposta de construção do Reator ARC foi originalmente adaptada do site TecMundo, que apresenta a estrutura do esquema do Reator ARC para a construção do tal, podendo ser encontrado em: https://www.tecmundo.com.br/area-42/37338-area-42-como-fazer-o-reator-arc-dohomem-de-ferro-video-.htm.

Seguindo o modelo de aprendizagem baseado em problemas, a sala era dividida por grupos de alunos e as aulas teóricas eram mínimas, apresentando os conteúdos por pequenos blocos, com listas de exercícios periódicas que iam da explicação dos componentes necessários para a resolução da mesma, até pequenos problemas eletrônicos 
para serem construídos. Todos os conceitos envolvidos estavam ligados à execução do projeto final para a elaboração do Reator ARC, que segue o modelo de aprendizagem ativa baseada em projetos. Após a conclusão de 5 listas de exercícios contendo um conteúdo autoexplicativo sobre como funcionam os componentes básicos a serem aprendidos é iniciada a construção do circuito eletrônico do Reator ARC. O circuito a ser desenvolvido se encontra nas experiências práticas 6,7 e 8 .

As aulas teóricas ministradas são de aproximadamente 10\% da carga horária da disciplina (6 horas de 60 horas), e então os alunos são encaminhados ao laboratório de Eletrônica e Sistemas Embarcados (LESE), onde ocorre todo o desenvolvimento prático das listas de exercícios propostas e do projeto final do Reator ARC. No LESE encontrase, também, a realização do projeto de Reciclagem e Reutilização de Equipamentos eletroeletrônicos - PRREE (SANTOS, 2018), que já ocorre a mais de 5 anos na instituição, onde situam-se os dispositivos eletroeletrônicos como protoboard, resistores, transistores, diodos, circuitos integrados (CIs), multímetros, entre outros.

Esses alunos ficam sempre sob a supervisão do professor responsável durante as aulas lecionadas nesse laboratório e também com a ajuda de seus monitores. Essas atividades são determinadas para serem executadas em duplas, e é necessário a confecção de um relatório para cada atividade (listas de exercícios). Por meio destes relatórios que o docente responsável pela disciplina pode avaliar o aprendizado dos alunos.

\subsection{NE555}

O CI NE555 é um componente comumente utilizado na eletrônica pelos seus benefícios, tais como baixo custo e de fácil utilização, apresentado na Figura $2 \mathrm{com}$ as representações do circuito integrado e de seu modelo esquemático. Também conhecido como oscilador ou temporizador, o NE555 capaz de gerar um clock na sua saída variando de microssegundos até minutos, que pode ser ajustado por meio de um potenciômetro, que de acordo com a variação de sua resistividade pode regular a velocidade com que o capacitor de temporização carregua/descarrega. Além dessas aplicações, o NE555 contém três modos de operação que são monoestável, estável e biestável (DE LIMA, 2011).

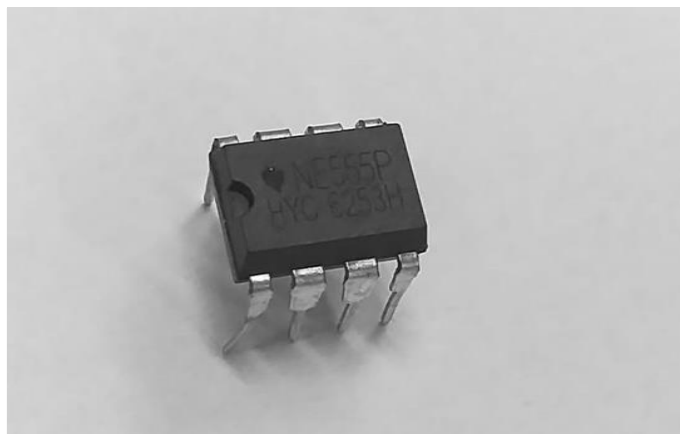

(a)

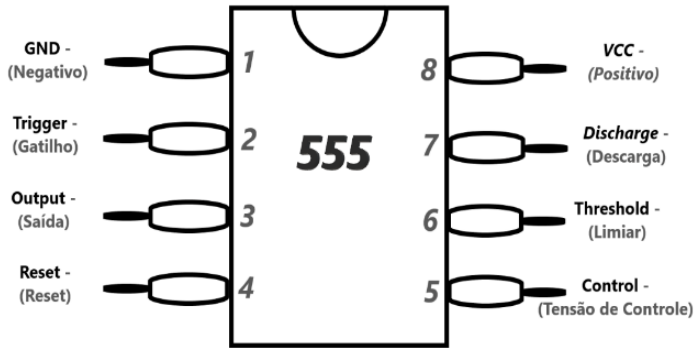

(b)

Figura 2. CI NE555 - (a) Circuito integrado - (b) Diagrama Esquemático Fonte: (a) Próprio autor - (b) https://www.renesas.com/br/en/www/doc/datasheet/icm7555-56.pdf

Possuindo 8 pinos, apresentado em invólucro DIL, o NE555 possui alimentação que pode ser feita com tensões entre 5 e $18 \mathrm{~V}$, onde cada pino possui uma função específica, apresentados na Tabela 1. 
Tabela 1 - Denotação da funcionalidade dos pinos do Circuito Integrado NE555

\begin{tabular}{|c|l|}
\hline Pinos & \multicolumn{1}{|c|}{ Funcionalidades } \\
\hline 1 & Funciona como o GND, chamado de Terra \\
\hline 2 & trigger, gatilho que ativa o modo biestável \\
\hline 3 & Saída de dados \\
\hline 4 & Função Reset onde se pode reestabelecer dados \\
\hline 5 & Controle de tensão \\
\hline 6 & Desativa o modo biestável interno e a saída, quando estiver $2 / 3$ da tensão VCC \\
\hline 7 & Utilizado para descarregar um capacitor \\
\hline 8 & Alimentação positiva \\
\hline
\end{tabular}

Fonte: Adaptado de (De LIMA, 2011).

\subsection{CD4017}

O circuito contador de décadas 4017, é apresentado na Figura 3 com as representações do circuito integrado e de seu diagrama esquemático, com características que permitem sua conexão com outros CIs, como o NE555. É um CI de fácil manipulação e compreensão, onde uma de suas utilizações é como um sequenciador, onde é capaz de se realizar uma sequência de ligamento/desligamento de luz (BRAGA, 2017). Possuindo 16 pinos, apresenta alimentação de 3 a $15 \mathrm{~V}$ apresentado em invólucro DIL, onde a funcionalidade de cada pino é apresentada na Tabela 2.

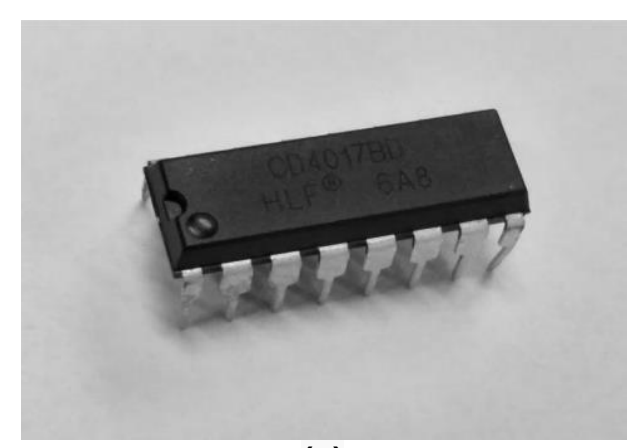

(a)

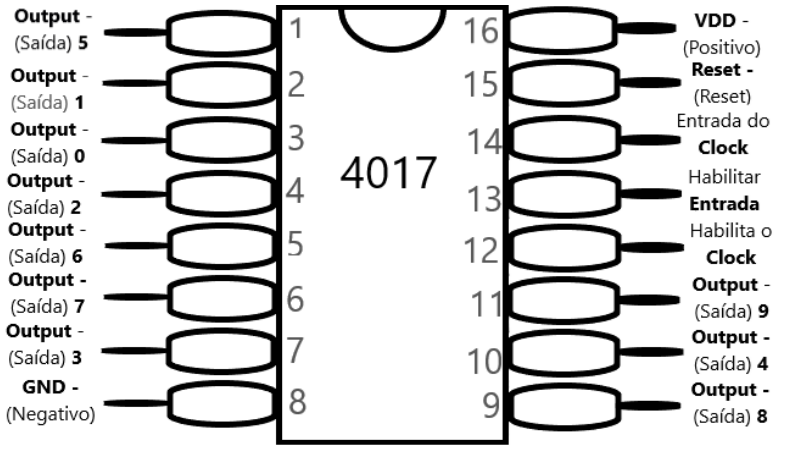

(b)

Figura 3. CI CD4017 - (a) Circuito integrado - (b) Diagrama Esquemático. Fonte: (a) Próprio autor - (b)

https://www.renesas.com/br/en/www/doc/datasheet/cd4017bms-22bms.pdf

Tabela 2. Denotação da funcionalidade dos pinos do Circuito Integrado 4017.

\begin{tabular}{|c|l|}
\hline Pinos & \multicolumn{1}{c|}{ Funcionalidades } \\
\hline $1-8,9-11$ & Saídas de dados \\
\hline 8 & Porta GND, comumente chamada de Terra \\
\hline 12 & Executa \\
\hline 13 & Habilita o clock \\
\hline 14 & Entrada do clock \\
\hline 15 & Reset para se reestabelecer os dados \\
\hline 16 & Alimentação positiva \\
\hline
\end{tabular}

Fonte: Próprio autor. 


\subsection{Construção do Reator ARC}

O circuito a ser desenvolvido na $6^{a}$ experiência prática é demonstrado na Figura 4. Neste exercício o aluno iniciará a construção da primeira parte do reator, que se refere a um oscilador com frequência variável.

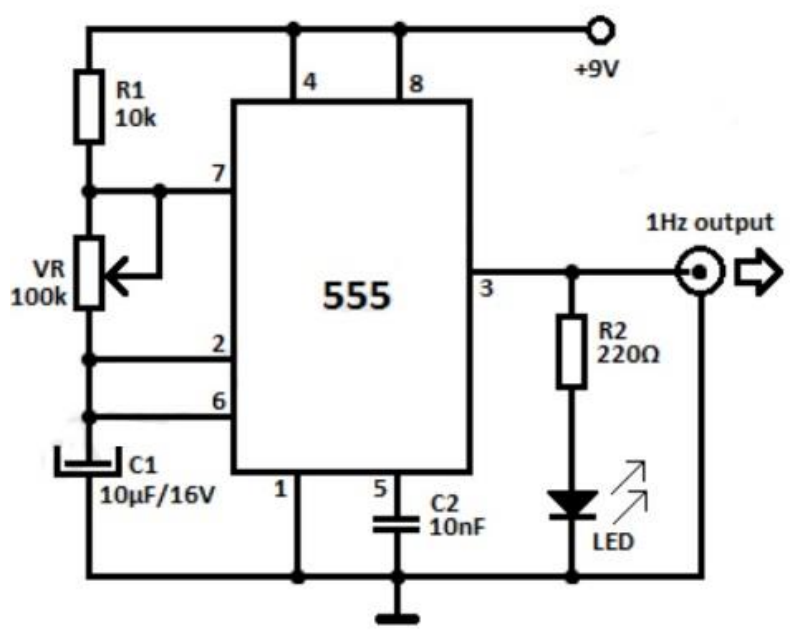

Figura 4. CI NE555 como Oscilador.

Fonte: https://drive.google.com/file/d/0B-vs7kVD3ipMREtCeGdPbWdnMTQ/view.

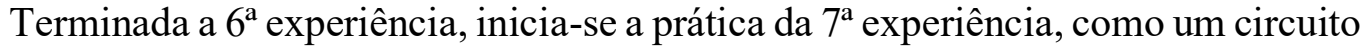
complementar ao oscilador (Figura 4), que completa o circuito eletrônico do Reator ARC. $\mathrm{O}$ projeto do circuito digital do oscilador com frequência variável juntamente com o CI CD4017 é apresentado na figura 5, e o projeto da placa de circuito impresso é apresentado na Figura 6. Na Figura 5 cada uma das dez saídas do CI CD4017 é conectado a um LED, e a saída D1 é conectada a outro LED. O CI NE555 serve como um oscilador de frequência para os pulsos de clock que servirão de entrada para o CD4017 o qual, a partir de um potenciômetro no NE555 se varia a frequência com que os pulsos serão enviados ao CD4017 aumentando ou não a frequência com que cada LED ativa/desativa.

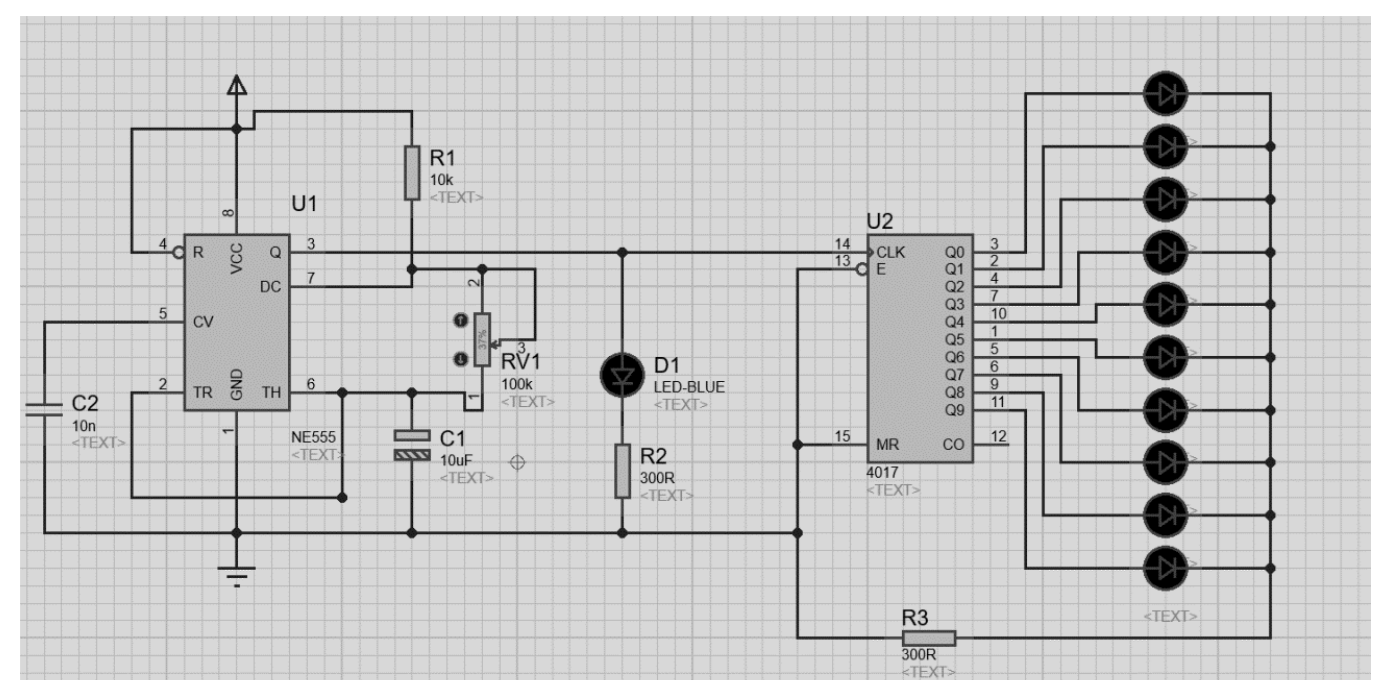

Figura 5. Projeto de circuito lógico para a combinação do CI NE555 conectado ao Cl CD4017.

Fonte: https://drive.google.com/file/d/OB-vs7kVD3ipMM2I5R0xFSXIRZEk/view. 


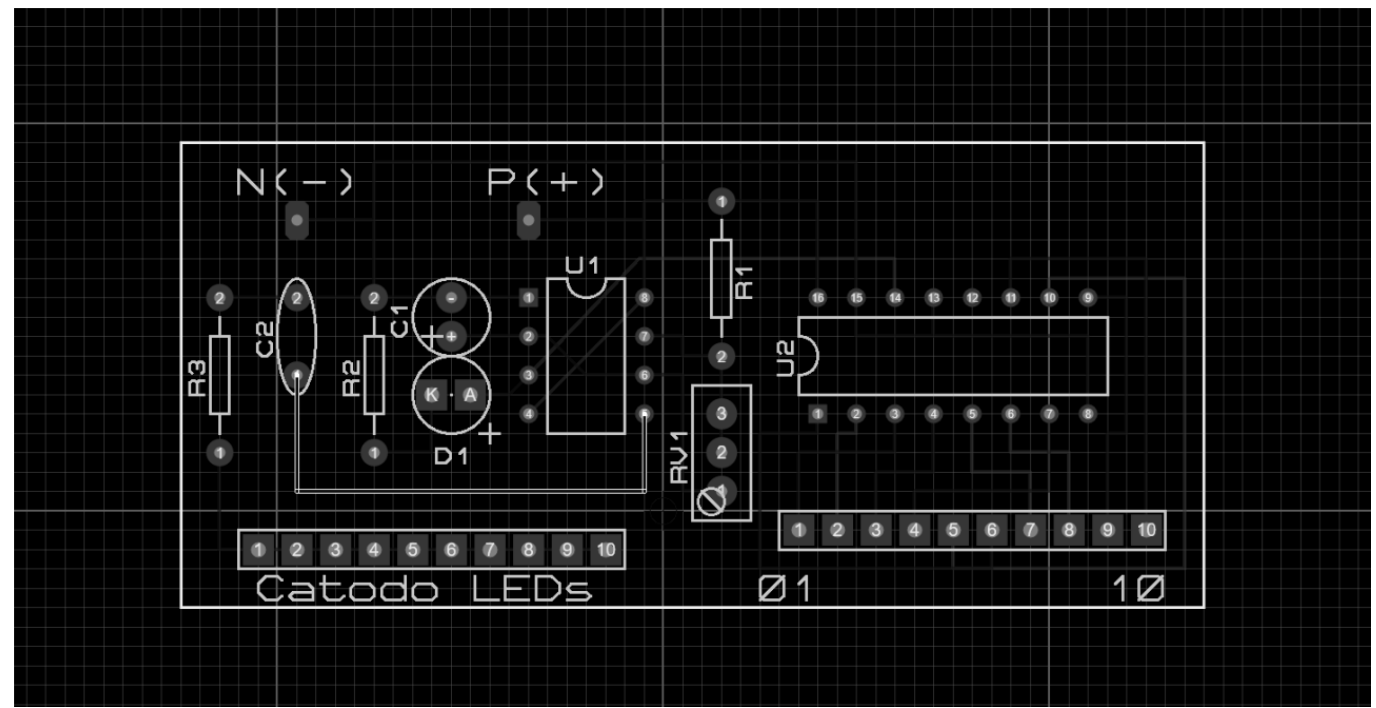

Figura 6. Projeto da placa de circuito impresso para a combinação dos Cls NE555 com o CI ND4017.

Fonte: https://drive.google.com/file/d/0B-vs7kVD3ipMM2I5R0xFSXIRZEk/view.

Parte-se então para a prototipagem do projeto da placa de circuito impresso, apresentado na Figura 6. A $8^{\circ}$ e última experiência é a prototipação e testes do Reator ARC das combinações dos circuitos, apresentada na Figura 7. A Figura 7 exibe todos os componentes utilizados pelas Figuras 5 e 6 já com a adição dos LEDs para a iluminação do reator ARC. Nota-se à esquerda da Figura 7 um pequeno círculo formado por $10 \mathrm{LEDs}$, os quais são iluminadas sequencialmente com a velocidade controlada por um potenciômetro, e o LED mais a direta é a iluminação central do reator que sempre fica ativa.

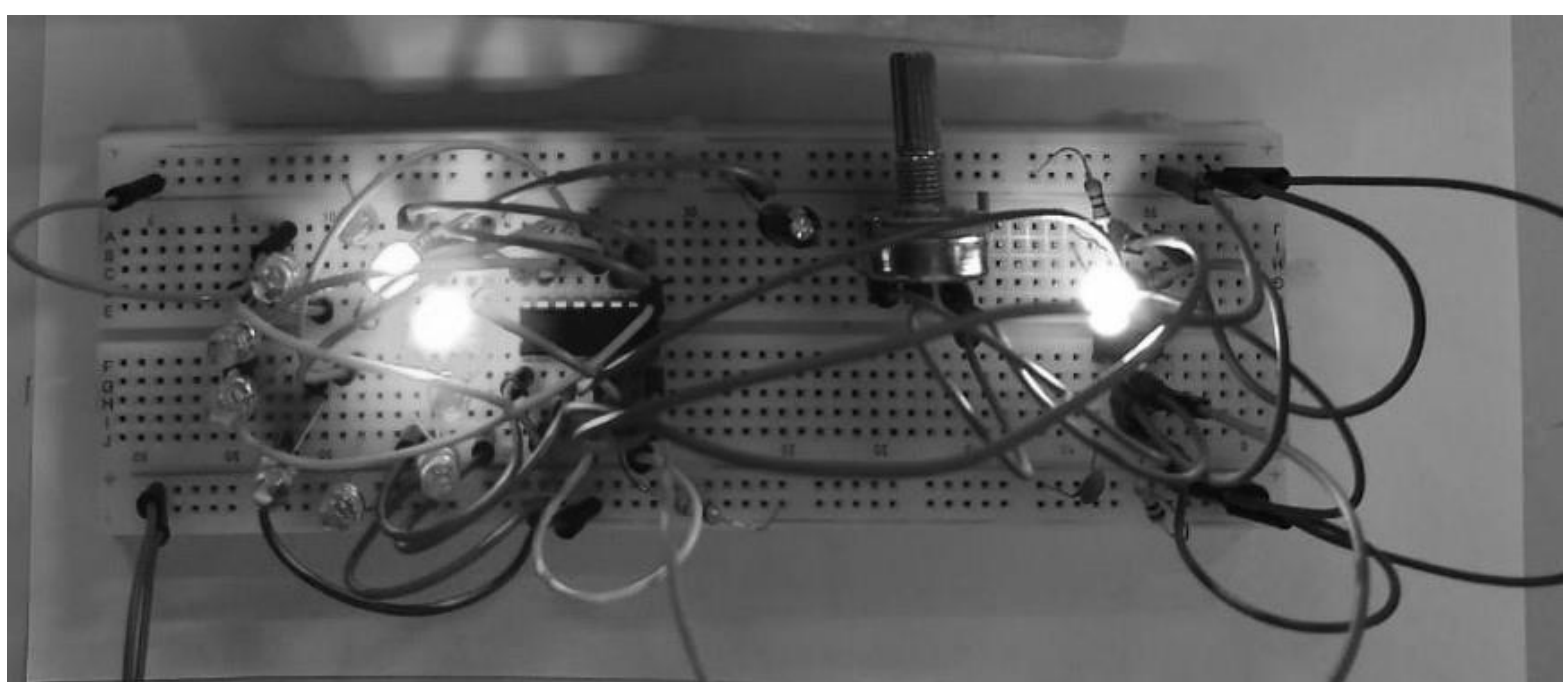

Figura 7. Prototipagem do Reator ARC.

Fonte: Próprio autor.

Como o LESE não possui uma fresa para construir placas de circuito impresso, a prototipação da Figura 7 foi construída utilizando-se placas ilhadas. A placa ilhada e os circuitos são inseridos dentro de um cap de PVC de $100 \mathrm{~mm}$, onde se cola em suas bordas internas um tubo de cola quente grosso. Este tubo de cola quente possui furos, embaixo, igualmente espaçados, para conter a mesma quantidade de LEDs a serem iluminados sequencialmente (Figura 7). No meio do Reator se posiciona uma capa meio translúcida 
onde se posicionará o LED central, e a fonte de alimentação é posicionada externamente para uma bateria de $9 \mathrm{~V}$. As demais adições como o desenho central do reator e adereços ao tubo de cola quente que irá piscar sequencialmente os LEDs são meramente à escolha de cada aluno utilizando de sua criatividade. A Figura 8 apresenta dois modelos de Reator ARC finalizados.
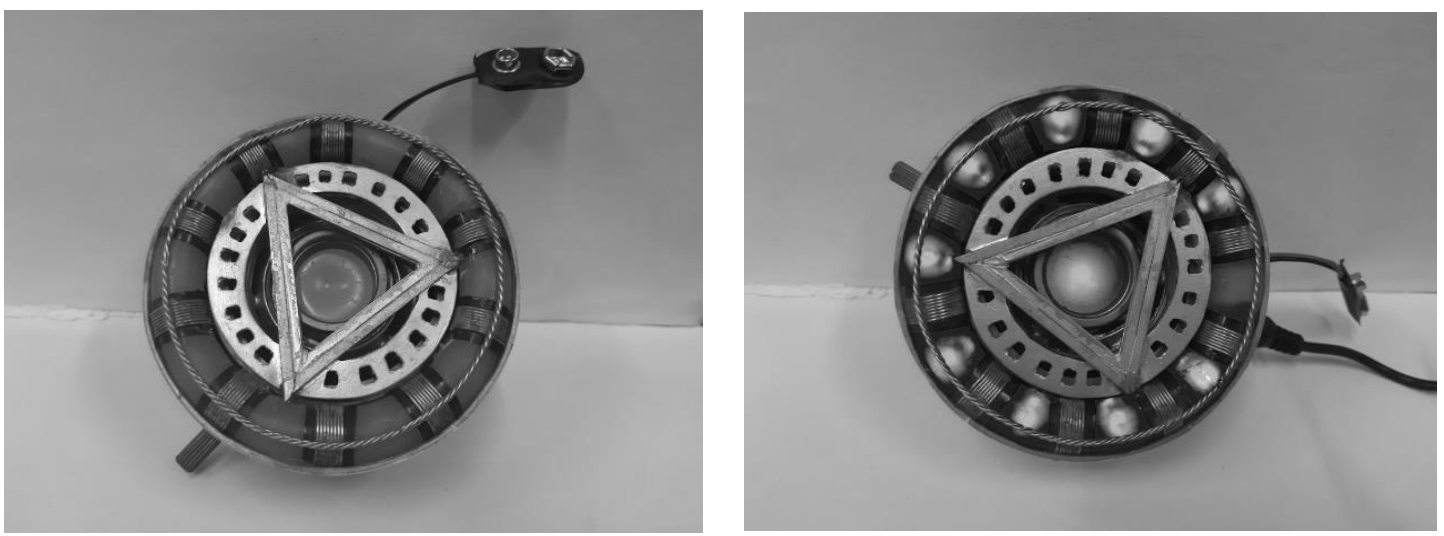

Figura 8. Modelos de Reator ARC finalizados. Fonte: Próprio autor.

\section{Resultados e Discussões}

A disciplina de Fundamentos de Eletrônica deu-se início no primeiro semestre de 2015 (2015/1), mas a inserção da proposta de desenvolvimento do Reator ARC deu-se início em 2017/1. Por meio de acesso a dados da Supervisão Acadêmica da UNEMAT do Campus de Alto Araguaia se construiu um gráfico de desistências e permanências de alunos na disciplina de Fundamentos de Eletrônica desde seu início em 2015/1, até a última aquisição realizada que foi em 2019/1. Este gráfico é apresentado na Figura 9.

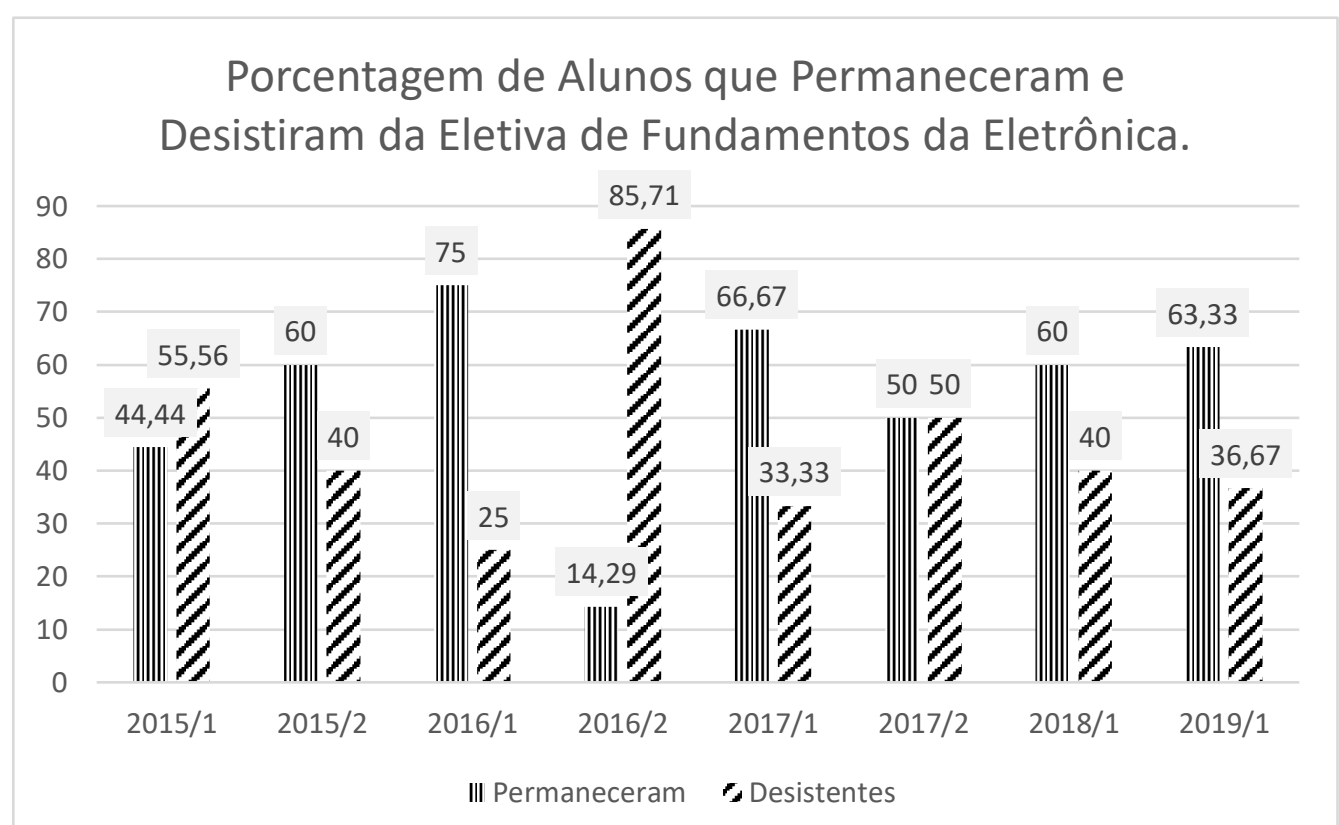

Figura 9. Gráfico de permanência/desistência de alunos na disciplina de Fundamentos de Eletrônica.

Fonte: Próprio autor. 
Avaliando a Figura 9 de 2015/1 até 2016/2, onde o projeto de desenvolvimento do Reator ARC ainda não tinha sido iniciado, a média da taxa de desistências foi de $51,39 \%$, e de $48,43 \%$ para a permanência. Após a inserção do projeto de elaboração do Reator ARC em 2017/1 até 2019/1 a média das taxas de desistência caíram para 40\% e a de permanência subiu para $60 \%$. Uma das razões principais deste estudo foi a grande desistência em 2016/2 que atingiu acima de 80\%. A partir de 2017/2 o crescimento gradativo de permanência dos alunos nesta disciplina mostrou que a proposta de utilização de metodologias ativas de aprendizagem obteve um grande sucesso no quesito de redução de desistências, pelo menos para esta disciplina.

No trabalho de (CARVALHO; SANTOS; NAKAMURA; OLIVEIRA, 2019) uma avaliação muito próxima foi realizada. Foram avaliados alunos formados e desistentes dos sexos masculino e feminino para os cursos de Ciência da Computação, Engenharia da Computação e Engenharia de Software da UFAM entre 2012 e 2017. Os números foram alarmantes, com mais de $60 \%$ de desistência para os homens e mais de $13 \%$ para as mulheres. Um dado muito interessante apresentado pelos autores foi de que o desempenho acadêmico no $1^{\circ}$ período letivo é um bom estimador do coeficiente de rendimento e taxa de aprovação nas disciplinas seguintes. Como dito anteriormente, as causas para estes números são complicadas que vão de gastos financeiros à gestão universitária e metodologias de ensino aplicadas. Seguindo o mesmo preceito de (CARVALHO; SANTOS; NAKAMURA; OLIVEIRA, 2019) a disciplina escolhida não era do primeiro semestre letivo, mas era dos semestres iniciais do curso de Ciência da Computação.

A redução de evasão de uma disciplina indica que o procedimento de ensino aprendizagem funcionou para aquela determinada situação. Este tipo de trabalho poderia ser replicado para outras disciplinas, mas não necessariamente ter-se-ia o mesmo índice de sucesso, pois temos as particularidades de cada disciplina e de cada docente. Mesmo assim o resultado alcançado melhorou os índices de evasão/permanência de alunos no curso.

As metodologias ativas de aprendizagem utilizadas mostraram ser bastante eficientes para o processo de ensino-aprendizagem dos alunos, pois percebeu-se um maior empenho em se aprender, e para isso buscavam o conhecimento e relatavam o que aprenderam através de seus relatórios. Como era de se esperar das metodologias ativas de aprendizagem, este maior empenho e motivação acarretou em uma excessiva troca de informações entre diferentes grupos de experimentos, mostrando um maior engajamento dos alunos para com a disciplina e conceitos envolvidos.

\section{Conclusão}

Duas metodologias de aprendizagem ativas foram utilizadas, sendo por projetos e por problemas, na disciplina de Fundamentos de Eletrônica do $3^{\circ}$ semestre do curso de Ciência da Computação da UNEMAT no Campus de Alto Araguaia. A principal razão para a utilização destas metodologias ativas foram os altos índices de evasão do curso, e da disciplina, como ilustrado pela Figura 9.

Esta nova abordagem, trazendo elementos interessantes como o tema do Homem de Ferro, trouxe uma melhor interação e motivação para os alunos aumentando o índice de permanência destes alunos na disciplina, reduzindo o índice de desistência da mesma, 
e possivelmente do curso. Este estudo mostrou um bom resultado na forma com que foi inserido, ou seja, em uma determinada disciplina de um determinado curso. Novos estudos podem ser realizados a fim de estender a utilização destas novas metodologias de ensino-aprendizagem em outras disciplinas do mesmo curso, tornando-o mais atrativo e consequentemente reduzindo-se os índices de evasão.

Claro, como explicado anteriormente, a forma de ensino-aprendizagem não é a única solução para a redução da evasão. Existem outros elementos que provocam evasão e não estão atrelados necessariamente a metodologias educacionais empregadas em uma disciplina. O perfil socio-econômico, o acesso do aluno aos programas de bolsas, recursos disponibilizados tanto pela universidade quanto pela própria cidade para que esse aluno venha se sentir atraído e também ache-se evolvido trazendo sua permanência e êxito, além da adequação dos conteúdos da disciplina ao perfil do curso e do egresso, são fatores que se não bem preparados e avaliados fazem com que a evasão de um curso superior cresça.

\section{Referências}

ALBRECHT, L. D.; KRÜGER, V. Metodologia tradicional x Metodologia diferenciada: a opinião de alunos. Revista Unijuí, Ijuí, n. 33, 2013.

BORGES, T. S.; ALENCAR, G. Metodologias ativas na promoção da formação crítica do estudante: o uso das metodologias ativas como recurso didático na formação crítica do estudante do ensino superior. Cairu em revista, v. 3, n. 4, p. 119-143, 2014.

BRAGA, N. C. Eletrônica Analógica. [s.1.] Editora Newton C. Braga, 2016.

BRAGA, N. C. O Circuito Integrado 4017. [s.l.] Editora Newton C. Braga, 2017.

GEWEHR, D. et al. Metodologias ativas de ensino e de aprendizagem: uma abordagem de iniciação à pesquisa. Ensino \& Pesquisa, v. 14, n. 01, 2016.

LABS, S. D. Os 4 pilares da metodologia de trabalho do Google. Disponível em: <https://www.startse.com/noticia/empreendedores/10681/os-4-pilares-da-metodologiade-trabalho-do-google>. Acesso em: 17 set. 2019.

LÁZARO, A. C.; SATO, M. A. V.; TEZANI, T. C. R. Metodologias ativas no ensino superior: o papel do docente no ensino presencial. CIET: EnPED, 2018.

MORAN, J. Metodologias ativas e modelos híbridos na educação. S. YAEGASHI e outros (Orgs). Novas Tecnologias Digitais: Reflexões sobre mediação, aprendizagem e desenvolvimento. Curitiba: CRV, p. 23-35, 2017.

OLIVEIRA, L. R. de et al. Metodologias ativas de ensino-aprendizagem e suas convergências com as Tecnologias Digitais de Informação e Comunicação. 2015.

SILVA, R. dos S. da. A neurociência como ferramenta para o ensino de ciências e biologia. 2019.

SILVA, S. M. Motivando crianças e jovens em ciência exatas, para um futuro brilhante. $2018 . \quad$ Disponível em: <https://drive.google.com/drive/folders/1o9UiRnoKVixbtvWbkU3-fkCR84mvJbs5>. 
TEODORO, N. M. Metodologia de ensino: Uma contribuição pedagógica para o processo de aprendizagem da diferenciação. Metodologia de ensino: Uma contribuição pedagógica para o processo de aprendizagem da diferenciação, p. 22, [s.d.]

VALLIM, M. B. R. et al. Incentivando carreiras na área tecnológica através da robótica educacional. Anais Do, v. 37, 2009.

VANESSA FAJARDO E FLAVIA FOREQUE. 7 de cada 10 alunos do ensino médio têm nível insuficiente em português e matemática, diz MEC. Disponível em: $<$ https://g1.globo.com/educacao/noticia/2018/08/30/7-de-cada-10-alunos-do-ensinomedio-tem-nivel-insuficiente-em-portugues-e-matematica-diz-mec.ghtml>. Acesso em: 12 jun. 2019. 
VIII Escola Regional de Informática de Goiás, Goiânia - GO, 11 a 13 de Novembro de 2020. 